\title{
LUCRO INFLACIONÁRIO E FLUXO DE CAIXA
}

\author{
Autor: Geraldo Barbieri \\ Professor Doutor da FEA/USP \\ Pesquisador da FIPECAFI
}

\section{INTRODUÇÃO}

Atualmente, no Brasil muitas empresas, ao elaborarem as suas demonstrações contábeis, estão apurando, como parte integrante do resultado, o famigerado "lucro inflacionário", também definido por muitos como "lucro fictício".

Em seu artigo "Contabilidade versus Fluxo de Caixa", o professor Eliseu Martins (1990), afirma, "O Balanço e a demonstração de resultado, se elaborados à luz do custo histórico e na ausência de inflação, são as distribuições lógicas e racionais ao longo do tempo do Fluxo de Caixa da Empresa".

E havendo inflação, para que as demonstrações representem melhor a realidade, Martins 1990, conclui:

Se consideramos que há necessidade de trabalharmos na inflação com uma moeda mais confiável, precisamos, obrigatoriamente, inserir na Contabilidade, com plenitude, a idéia da moeda constante e a valor presente.

Com base nas afirmações anteriores, parece simples concluir que todos os componentes do balanço e da demonstração de resultado já foram ou serão transformados em caixa em determinado momento.

Concordamos e até consideramos simples raciocinar da seguinte forma sobre as vendas que aparecem na Demonstração de resultado: se à vista já foram; se à prazo, há um dia definido de recebimento; portanto; a se trazerem as vendas a valor presente, tem-se noção de quanto será o caixa correspondente em moeda forte, no dia da operação. Na data do vencimento das duplicatas, subdividi-lo em duas partes: Receita de vendas e Receita de juros.

Talvez não seja tão simples entender a transformação de outras contas (como depreciação, despesas pagas antecipadamente etc.) em caixa quanto o seja em relação às vendas, mas muito já se escreveu sobre isso.

Este trabalho tem como objetivo principal, discutir a existência ou não de "lucro inflacionário" e, em caso afirmativo, em que momento ele se transforma em caixa.

\section{DEMONSTRAÇÕES CONTÁBEIS}

O objetivo principal da Contabilidade é o de prover seus usuários com demonstrações e análises de natureza, financeira, física e de produtividade, com relação à entidade objeto de contabilização ${ }^{1}$.

As empresas. Na forma de sociedade por ações, há muito tempo vêm publicando o balanço patrimonial e a demonstração do resultado do exercício.

\footnotetext{
${ }^{1}$ Estrutura Conceitual Básica da Contabilidade; trabalho originalmente desenvolvido pelo professor Sérgio de Iudícibus com o do IPECAFI, adotado pelo IBRACON e pela CVM, através da Deliberação nº. 29, de 5.02.86, p. 9 .
} 
O balanço retrata a situação da entidade em determinada data: pela sua característica absolutamente estática, pode ser cognominado de fotografia da empresa naquele momento.

A outra demonstração mencionada anteriormente, a do resultado do exercício, como a própria denominação sugere, já apresenta característica dinâmica e representa o fluxo de formação do resultado em determinado período.

Ao longo do tempo, percebeu-se a necessidade da elaboração de uma nova demonstração que representasse um novo fluxo, não restrito apenas ao de receitas e despesas, uma vez que a demonstração do resultado dá um fluxo de determinado período, mas relativo simplesmente às receitas e às despesas incorridas. A demonstração de resultado não é um fluxo completo de toda a movimentação financeira da entidade num lapso de tempo qualquer.

Nasce, então, a idéia da criação de outros fluxos contábeis, dos quais o que mais se difundiu foi o chamado "fluxo de fundos", a forma desse relatório, porém era bastante diversa.

Em outubro de 1963, o American Institute of Certified Public Accountants (AICPA), através da opinião n ${ }^{\circ} .3$ do Accountants Principles Board, sugeria a divulgação da demonstração do Fluxo de Fundos.

Em outubro de 1970, houve manifestação da Securities and Exchange Comission (SEC) no sentido de divulgar e detalhar o Fluxo de Fundos.

Já em março de 1971, o AICPA emitiu sua opinião $n^{\circ}$. 19, que entrou em vigor em 30 de setembro de 1971 e tornou obrigatória a apresentação do Fluxo de Fundos, mas com a denominação de "Demonstração das Alterações na Posição Financeira".

No Brasil, a partir de 31.12.78, com a entrada em vigor da obrigatoriedade de elaboração das demonstrações financeiras previstas na Lei $\mathrm{n}^{\circ}$. 6404/76, todas as Sociedades por Ações com Patrimônio Líquido igual ou maior que 20.000 ORTNs, na data do Balanço, passaram a ser obrigadas a publicar a Demonstração das Origens e Aplicações de Recursos.

Segundo o Prof. Eliseu Martins, 1988:

a Demonstração das Origens e Aplicações de Recursos (DOAR) é de difícil entendimento para as pessoas não bastante afeitas à técnica contábil ou à administração financeira e tem havido, no mundo inteiro, uma certa dificuldade de entendimento, porque, muitas vezes, a empresa produz grandes valores de resultado, mas esse resultado traz capital circulante líquido, insuficiente para a cobertura das necessidades da empresa.

Buscando alternativas para a verdadeira utilidade da Demonstração das Origens e Aplicações de Recursos, ao longo do tempo, principalmente nos últimos 15 anos, muitos trabalhos têm sido elaborados com base em diferentes alternativas.

A conclusão parece ser de que uma demonstração de Fluxo de Caixa tem maior utilidade do que a DOAR, por fornecer aos usuários uma melhor visão do fluxo dos recursos financeiros, reduzindo os problemas que têm impossibilitado uma utilização mais técnica, mais correta e mais completa da Demonstração das Origens e Aplicações de Recursos tradicional, como a que conhecemos ainda hoje no Brasil. 


\section{MODELOS DE FLUXO DE CAIXA}

A Norma Internacional de Contabilidade - NIC 7 (ou International Accounting Standard - IAS 7) trata da apresentação que resume, no período contábil, os recursos tornados disponíveis para financiar as atividades de uma empresa e o uso que tenha sido feito de tais fundos.

A NIC 7 foi aprovada em 1977; à época, o título dado ao relatório citado no parágrafo anterior foi "Demonstração das Mutações na Posição Financeira". Em 1992, o IAS 7 foi revisado; o título original é Cash Flow Statements e propõe dois modelos: O Método Indireto e o Método Direto.

O Financial Accounting Standards Board (FASB) começou seu projeto de reportar o fluxo de caixa no início da década de 80 e, em 31 de julho de 1986, publicou o Boletim $\mathrm{n}^{\circ}$. 23, propondo que as empresas norte-americanas passassem a apresentar um relatório de Fluxo de Caixa das Atividades Operacionais, em lugar da tradicional DOAR.

O Boletim no. 95 de 1987, Stament of Cash Flows, que tornou obrigatória a demonstração de fluxo de caixa como parte integrante das demonstrações financeiras em substituição às demonstrações de mutações na oposição financeira, já preconizava as duas formas de apresentação de Fluxo de Caixa adotadas pelo International Accounting Standards Committee (IASC), ou seja, o Método Indireto e Direto.

O Método Indireto consiste na demonstração dos recursos provenientes das atividades operacionais a partir do lucro líquido, ajustado pelos itens que afetam o resultado, mas que não modificam o caixa da empresa.

O Método Direto distinguiu-se do Indireto pela apresentação dos recursos provenientes das operações. Nele são demonstrados os recebimentos e pagamentos derivados das atividades operacionais da empresa, e não do lucro líquido ajustado.

Os pesquisadores, professores Sérgio de Iudícibus, Eliseu Martins e Ernesto Rubens Gelbcke, no Manual de Contabilidade das Sociedades por Ações da FIPECAFI, 1990, dizem que a Demonstração do Fluxo de Caixa, quando elaborada pelo Método Direto, é mais fácil de ser entendida.

O FASB em seu Boletim no. 95, embora apresente os dois modelos de Fluxo de Caixa, incentiva a publicação pelo Método Direto, no entanto, uma pesquisa efetuada pelo AICPA, 1993, nos Estados Unidos da América, mostra que a grande maioria das empresas publica o fluxo de caixa utilizando o Método Indireto. O resultado dessa pesquisa é apresentado a seguir:

\begin{tabular}{|l|c|c|c|c|c|}
\hline & 1992 & 1991 & 1990 & 1989 & 1988 \\
\hline Método Indireto & 585 & 585 & 585 & 583 & 526 \\
\hline Método Direto & 15 & 15 & 15 & 17 & 16 \\
\hline TOTAL & 600 & 600 & 600 & 600 & 542 \\
\hline
\end{tabular}

\section{SALDO CREDOR DE CORREÇÃO MONETÁRIA}

As Leis $n^{\circ}$ s. 2826 e 3740 , de 4 de setembro de 1956 e de 28 de novembro de 1958, respectivamente, facultaram às empresas aumentar seus capitais por meio do que se chamou "reavaliação" do Ativo Imobilizado, mas podemos dizer que a Lei $\mathrm{n}^{\circ} .4357$, de 16 de julho de 1964, representa a certidão de nascimento da correção monetária das demonstrações contábeis, pois tornou compulsória a correção de Ativo Imobilizado. Foi porém, com o advento da Lei nº. 6404, de 15 de dezembro de 
1976, que as sociedades por ações passaram a reconhecer os efeitos da inflação através da correção monetária dos grupos “Ativo Permanente" e "Patrimônio Líquido". E, em 1977, o Decreto-lei no. 1598, estendeu a obrigatoriedade da sistemática, introduzida para as sociedades por ações, para as demais empresas que apuravam seus resultados através do chamado lucro real.

Mesmo com o avanço atingido com a Lei ${ }^{\circ}$. 6404/76, as demonstrações contábeis foram perdendo qualidade à medida que os índices inflacionários foram se tornando elevados. Foi então que a Comissão de Valores Mobiliários - CVM, em 19 de maio de 1987, normalizou a chamada correção monetária integral, por meio da Instrução $n^{\circ}$. 64, obrigando as companhias abertas a apresentar demonstrações contábeis elaboradas conforme a metodologia preconizada nessa instrução. Podemos afirmar que a qualidade dessas demonstrações foi sensivelmente melhorada.

Ao longo do tempo, a metodologia da correção integral, através da publicação de várias outras instruções, sofreu uma evolução até que, em julho de 1992, foi editada a Instrução CVM nº. 191, atingindo um alto grau de perfeição nas demonstrações contábeis, quando elaboradas em conformidade com a mesma.

\section{VOLTANDO À CORREÇÃO MONETÁRIA CONFORME A LEI Nº 6404/76}

Embora tenhamos dito que a correção monetária pela Lei ${ }^{\circ}$. 6404/76 apresentou um avanço com relação às leis anteriores, devido à maneira de reconhecer o saldo da conta de Correção Monetária como oriundo das atualizações das contas de Ativo Permanente e Patrimônio Líquido, tem ocorrido muitos problemas com relação ao seu entendimento.

Normalmente, o que se comenta com respeito ao saldo da conta de Correção Monetária é que, se ele é devedor, não representa uma despesa que provocou saída de caixa e, quando é credor, também não significa uma receita que represente entrada de dinheiro.

Uma análise feita apenas com esse grau de simplicidade é altamente enganosa, pois há outros aspectos muito relevantes a serem incluídos, principalmente no caso de saldo credor.

Apesar de existirem, no Brasil, muitos trabalhos publicados que discutem esse assunto, a incompreensão do que, na sua essência, representa a conta de Correção Monetária do Balanço "infelizmente" permanece até os dias atuais.

A prova dessa incompreensão está manifestada na Lei $n^{\circ} .8920$, de 20 de julho de 1994, ao proibir as empresas públicas, as sociedades de economia mista e as demais pessoas jurídicas, controladas de forma direta ou indireta pelo Poder Público, de pagar dividendos e participações nos lucros com base em saldo credor de correção monetária.

\section{LUCRO INFLACIONÁRIO}

Segundo o professor Iudícibus (1990), "só existe lucro inflacionário quando a empresa contrata empréstimo à taxa nominal de juros menor do que a taxa de inflação".

Embora praticamente não haja mais no Brasil empréstimos contratados à taxa de juros negativa, algumas empresas vivem hoje uma situação até certo ponto estranha. Após o Plano real, o Banco Central do Brasil vem mantendo a taxa do dólar praticamente estável e, como a inflação ainda persiste, a taxas bem reduzidas, é verdade, em relação às vividas anteriormente, as empresas que têm passivos vinculados à variação do dólar estão obtendo lucros inflacionários. Poderíamos até dizer que esses passivos podem ser considerados empréstimos subsidiados. 


\section{REALIZAÇÃO LUCRO INFLACIONÁRIO}

A preocupação atual das empresas que tem parte de seu passivo vinculado à variação do dólar é de que elas estão obtendo lucro que não é caixa, uma vez que compraram imobilizados com empréstimos e, devido à metodologia de correção monetária da Lei ${ }^{\circ}{ }^{\circ} .6404 / 76$, estão ganhando, mas a realização financeira ainda não aconteceu.

Vamos, por meio de exemplos, discutir primeiramente a existência do lucro inflacionário e, depois, a sua realização financeira.

\section{Primeiro Exemplo}

Suponhamos que, em determinado período, a inflação medida pela variação da UMC (Unidade Monetária Contábil) tenha sido de 5\%, ou seja, a UMC de 31. 12. X0 $=\$ 100,00$ e a de 31.01.X1 $=$ $\$ 105,00$ e que as demonstrações contábeis sejam as seguintes:

\begin{tabular}{|l|c|c|}
\hline \multicolumn{1}{|c|}{ Balanços Societários (\$) } & $31.12 . X 0$ & $31.01 . \mathrm{X} 1$ \\
\hline ATIVO & 0 & 12.000 \\
\hline Caixa & 900.000 & 945.000 \\
\hline Terrenos & $\mathbf{9 0 0 . 0 0}$ & $\mathbf{9 5 7 . 0 0 0}$ \\
\hline & & 515.000 \\
\hline PASSIVO & 500.000 & 420.000 \\
\hline Empréstimos & 400.000 & 22.000 \\
\hline Capital + Correção Monetária & 0 & $\mathbf{9 5 7 . 0 0 0}$ \\
\hline Lucro do Exercício & $\mathbf{9 0 0 . 0 0 0}$ & \\
\hline
\end{tabular}

\begin{tabular}{|l|c|}
\hline Demonstração de Resultado em & Janeiro X1 (\$) (Societária) \\
\hline Receitas de aluguel & 82.000 \\
\hline Despesas diversas & $(70.000)$ \\
\hline Lucro Bruto & 12.000 \\
\hline Despesas Financeiras & $(15.000)$ \\
\hline Lucro Operacional & $(3.000)$ \\
\hline *Saldo da Correção Monetária & $\underline{25.000}$ \\
\hline Lucro Líquido & 22.000 \\
\hline
\end{tabular}

*Saldo da Correção Monetária

Correção de terrenos $=0,05 \times \$ 900.000=\$ 45.000$ Receita

Correção do Capital $=0,05 \times \$ 400.000=\$ 20.000$ Despesa

\section{$\$ 25.000$ Receita}

Outros dados:

a) os empréstimos foram contratados a juros nominais de $3 \%$ ao mês;

b) os juros apropriados e o pagamento do principal e juros serão feitos em 50 parcelas anuais a partir de X2;

c) as receitas de aluguel e despesas diversas foram recebidas e pagas respectivamente em 31.01.X1.

Até hoje, a análise mais comumente efetuada sobre o resultado, é a seguinte:

O lucro de \$22.000 é devido ao saldo credor de Correção Monetária (Receita). Antes da Correção Monetária, havia um prejuízo operacional de \$3.000. Como a Correção Monetária implantada pela Lei $n^{\circ}$. 6404/76 representa a contrapartida da correção de Ativo Permanente e do Patrimônio Líquido, portanto um "mero ajuste contábil", o lucro não poderá ser distribuído, pois não tem caixa. 


\section{- APLICAÇÃO DA METODOLOGIA DA CORREÇÃO INTEGRAL}

Primeiramente, vamos colocar os dois balanços, apresentados anteriormente em moeda de 31.01.X1.

\begin{tabular}{|l|r|r|}
\hline Balanços em moeda & De 31.01.X1 $(\$)$ & \\
\hline & $31.12 . X 0$ & 31.01. X1 \\
\hline ATIVO & Corrigido por 1,05 & 12.000 \\
\hline Caixa & 0 & 945.000 \\
\hline Terrenos & 945.000 & $\mathbf{9 5 7 . 0 0 0}$ \\
\hline & $\mathbf{9 4 5 . 0 0 0}$ & 515.000 \\
\hline PASSIVO & 525.000 & 420.000 \\
\hline Empréstimos & 420.000 & 22.00 \\
\hline & 0 & $\mathbf{9 5 7 . 0 0 0}$ \\
\hline
\end{tabular}

Como as receitas de aluguel e as despesas diversas ocorreram no último dia do mês, os valores em moeda de 31.01.X1 são exatamente os mesmos da legislação societária.

Demonstrações de Resultado em janeiro de X1 (\$)

\begin{tabular}{|l|l|l|l|l|}
\hline Datas & Histórico & $\$$ & UMC da data & Total em UMCs \\
\hline 31.12.X0 & Saldo & 500.000 & $\$ 100,00$ & $5.000,0000$ \\
\hline 31.01.X1 & Saldo que deveria existir & 500.000 & & $5.000,0000$ \\
\hline & Saldo existente & 515.000 & $\$ 105,00$ & $4.904,7619$ \\
\hline & Despesas Financeiras & 15.000 & & 95,2381 \\
\hline
\end{tabular}

Veja, em UMCs, houve um ganho uma vez que, embora não ocorrendo pagamentos, os empréstimos diminuíram de 95, 2381 UMC s, equivalente a $\$ 10.000=95,2381$ x $\$ 105,00$; portanto, a empresa teve despesas financeiras negativas.

A Demonstração de Resultado de janeiro, elaborada de acordo com a metodologia da Correção Integral, é a seguinte:

Demonstração de Resultado em janeiro de X1 (\$)

\begin{tabular}{|l|l|}
\hline Receitas de Aluguel & 82.000 \\
\hline Despesas diversas & $(\underline{70.000})$ \\
\hline Lucro Bruto & 12.000 \\
\hline Despesas Financeiras (negativas) & $\underline{10.000}$ \\
\hline Lucro Líquido & 22.000 \\
\hline
\end{tabular}

Concluímos, com este exemplo, que, quando a empresa tem empréstimos subsidiados, existe o que podemos chamar de "lucro inflacionário", mas esse lucro é oriundo da diferença entre a taxa de juros e a inflação do período multiplicada pelo valor do empréstimo, e não do saldo credor de correção monetária.

No exemplo, ele representa os:

$\$ 10.000=(0,050,03) \times \$ 500.000$ 


\section{- DISTRIBUIÇÃO DO LUCRO INFLACIONÁRIO}

Segundo exemplo

No primeiro exemplo, poderíamos dizer que a empresa comprou os terrenos usando $\$ 400.000$ de capital próprio e $\$ 500.000$ de capital de terceiros. Vamos supor que, sabedora do subsídio para o período, ela não adquiriu terrenos no valor de $\$ 900.000$ e distribui parte do empréstimo como lucro.

É correto distribuir parte do empréstimo como lucro?

Existe uma celeuma muito grande com relação ao lucro inflacionário; conforme dissemos anteriormente, alguns pesquisadores chegam até dizer, quando ocorre esse fato, que o resultado é fictício.

Podemos afirmar que as pessoas que pensam dessa forma não fizeram uma análise aprofundada sobre o assunto.

Analisando o problema, verificamos que, quando a empresa consegue empréstimos subsidiados, ela tem um ganho no futuro, ou seja, à medida que for passando o tempo, a dívida irá diminuindo em termos reais, surgindo então o discutido, e às vezes, mal entendido lucro inflacionário.

A colocação normal é que esse lucro só pode ser distribuído após a realização do ativo (inclusive esse foi o entendimento dado pela Lei $\mathrm{n}^{\circ}$. 8920, de 20.07.94, no caso das estatais).

Nosso ponto de vista é que, ao utilizar todo o empréstimo para adquirir terrenos, uma parcela desse empréstimo transformar-se-á em lucro no futuro, mas a realização financeira desse lucro já aconteceu no momento que o dinheiro entrou em sua conta.

Assim, o que vamos propor neste exemplo é que a empresa calcule, na data do recebimento do empréstimo, o lucro futuro, não invista esse valor em ativo de longo prazo e que poderá até fazer uma distribuição antecipada.

Supondo que a empresa conheça a taxa de juros e a inflação para o período, criamos a fórmula que vem a seguir, para definir o valor do lucro a ser distribuído:

$\mathrm{LIA}=\mathrm{E} \times[1(1+\mathrm{i} / 1+\mathrm{I})]$

Em que:

LIA = Lucro Inflacionário;

$\mathrm{E}=$ Valor do Empréstimo;

I = Taxa nominal de juros;

I = Taxa de inflação prevista.

Substituindo os dados na fórmula temos:

$\mathrm{LIA}=\$ 500.000 \times(11,03 / 1,05)=\$ 9.524$

Uma vez definido o lucro a ser distribuído antecipadamente, há necessidade agora de determinar o valor do ativo de longa duração a ser adquirido. 
Para tanto, vamos utilizar a fórmula seguinte:

$\mathrm{T}=\mathrm{K}+\mathrm{E}$ LIA

Em que:

$\mathrm{T}=$ Valor de compra dos terrenos;

$\mathrm{K}$ = Capital próprio;

$\mathrm{E}=$ Empréstimo;

LIA = Lucro inflacionário antecipado.

Substituindo, temos:

$\mathrm{T}=\$ 400.000+\$ 500.000-\$ 9.524=\$ 890.476$

Demonstrações Contábeis Societárias Balanço (\$)

\begin{tabular}{|l|c|c|}
\hline & $31.12 . X 0$ & $31.01 . X 1$ \\
\hline ATIVO & 0 & 12.000 \\
\hline Caixa & 890.476 & 935.000 \\
\hline Terrenos & $\mathbf{8 9 0 . 4 7 6}$ & $\mathbf{9 4 7 . 0 0 0}$ \\
\hline PASSIVO & & 515.000 \\
\hline Empréstimos & 500.000 & 420.000 \\
\hline Capital + Correção Monetária & 400.000 & 12.000 \\
\hline Lucros Acumulados & $(9.524)$ & $\mathbf{9 4 7 . 0 0 0}$ \\
\hline
\end{tabular}

A aquisição de terrenos por um valor menor do que no exemplo poderia ensejar a diminuição proporcional das Receitas de Aluguel e Despesas Diversas. Para que os resultados sejam iguais ao anterior, a fim de que possamos ter um aproveitamento didático do exemplo, consideramos que as Receitas e Despesas se mantiveram.

Demonstração de Resultado (\$)

\begin{tabular}{|l|l|}
\hline Receitas de aluguel & 82.000 \\
\hline Despesas Diversas & $(\underline{70.000})$ \\
\hline Lucro Bruto & 12.000 \\
\hline Despesas Financeiras & $(15.000)$ \\
\hline Lucro Operacional & $(3.000)$ \\
\hline *Saldo da Correção Monetária & 25.000 \\
\hline Lucro Líquido & 22.000 \\
\hline *Saldo da Correção Monetária & \\
Terrenos 0,05 x \$890.476 & $=\$ 44.524$ Receita \\
Capital 0,05 x $\$ 400.000$ & $=\$ 20.000$ Despesa \\
Lucros Acumulados 0,05 x $(\$ 9.524)$ & $=\$ 476$ Receita \\
& $\$ \mathbf{2 5 . 0 0 0}$ Receita
\end{tabular}

Na elaboração das demonstrações em moeda constante, vamos propor, para efeito de simplificação, que as receitas e despesas, da mesma forma que no primeiro exemplo, ocorreram no final do mês e à vista.

Dessa maneira, a Demonstração de Resultado em moeda constante será a mesma desenvolvida no primeiro exemplo, que é seguinte: 
Demonstração de Resultado em janeiro de X1 (\$)

\begin{tabular}{|l|l|}
\hline Receitas de Aluguel & 82.000 \\
\hline Despesas Diversas & $(70.000)$ \\
\hline Lucro Bruto & 12.000 \\
\hline Despesas Financeiras (negativas) & 10.000 \\
\hline Lucro Líquido & 22.000 \\
\hline
\end{tabular}

No manual de Contabilidade das Sociedades por Ações, da FIPECAFI (Op. cit., 1990), Iudícibus afirma: "O Lucro Inflacionário só existe quando há subsídios com relação às taxas de juros".

Assim, sendo podemos concluir, com este exemplo, que aquele lucro tão discutido quanto à sua realização financeira, muitas vezes definido como lucro fictício, poderia ser distribuído mesmo antes de ser realizado contábil e economicamente, pois a sua realização financeira ocorreu na data da contratação do empréstimo.

Análise da distribuição do lucro:

Lucro do exercício $\$ 22.000$

Lucro distribuído antecipadamente $\$ 9.524 \times 1.05=(\$ 10.000)$

Lucro a distribuir (saldo de caixa) $\$ \underline{\$ 12.000^{10}}$

Com relação a esse lucro antecipado, alguém poderia pensar: "se não tenho certeza sobre a taxa de inflação, não sei qual será o valor do lucro".

Veja que, para se apurar o lucro da empresa são feitas várias previsões (taxa de depreciação, taxa de amortização, devedores duvidosos etc.), portanto, o valor exato do lucro sempre está dependendo de que essas previsões ocorram.

Assim, podemos perfeitamente trabalhar com taxa de inflação prevista. Mas o nosso objetivo, com este trabalho, não é discutir o valor do lucro inflacionário, e sim a sua existência e o momento de sua realização financeira.

Achamos que, com esses exemplos, podemos concluir que ele existe e a sua realização financeira ocorre no momento em que o empréstimo subsidiado entra no caixa da empresa.

\section{O GANHO INFLACIONÁRIO DOS BANCOS}

Até o momento discorremos sobre o lucro inflacionário, mas sempre relacionado a empréstimo subsidiado e aplicações em imobilizado.

Vamos agora, através de um exemplo bem simplificado, discutir o lucro gerado pelo ganho com depósitos à vista e a sua relação com o fluxo de caixa.

Determinado Banco iniciou suas atividades em 31.01.X1.

Nesse dia, ocorreram as seguintes operações:

Realizou Capital em dinheiro $\$ 100.000$

Recebeu Depósitos à vista $\$ 400.000$

Efetuou Operações de crédito $\$ 500.000$

Em fevereiro, não foram efetuadas novas operações. 
Para efeito de simplificação do exemplo, estamos supondo que a taxa de juros nominal sobre operações de crédito foi somente a variação das UMCs. UMCs de 31.01.X1 = \$105,00 e 28.02.X1 $=\$ 110,25$.

\begin{tabular}{|l|c|c|}
\hline & $31.01 . X 1$ & $28.02 . X 1$ \\
\hline ATIVO & & \\
\hline Operações de crédito & 500.000 & 525.000 \\
\hline & $\mathbf{5 0 0 . 0 0 0}$ & $\mathbf{5 2 5 . 0 0 0}$ \\
\hline PASSIVO & & \\
\hline Depósito à vista & 400.000 & 400.000 \\
\hline Capital+Correção Monetária & 100.000 & 105.000 \\
\hline Lucro do Exercício & 0 & 20.000 \\
\hline & $\mathbf{5 0 0 . 0 0 0}$ & $\mathbf{5 2 5 . 0 0 0}$ \\
\hline
\end{tabular}

Cálculos para a elaboração de demonstrações Complementares:

\section{- Transformação em UMCs}

Receitas de Operações de Crédito:

Janeiro $=0$

Fevereiro:

\begin{tabular}{|l|l|l|l|c|}
\hline Datas & Histórico & $\$$ & UMC da data & Total em UMCs \\
\hline 31.01.X1 & Saldo & 500.000 & $\$ 105,00$ & $4.761,9048$ \\
\hline & Saldo que deveria existir & 500.000 & & $4.761,9048$ \\
\hline & Saldo existente & 525.000 & $\$ 110,25$ & $(4.761,9048)$ \\
\hline & Receitas de Operações de Crédito & 25.000 & & 0 \\
\hline
\end{tabular}

Ganho nos depostos à vista:

Janeiro $=0$

Fevereiro:

\begin{tabular}{|l|l|l|l|l|}
\hline Datas & Histórico & $\$$ & UMC da data & Total em UMCs \\
\hline 31.01.X1 & Saldo & 400.000 & $\$ 105,00$ & $3.809,5238$ \\
\hline & Saldo que deveria existir & 400.000 & & $3.809,5238$ \\
\hline & Saldo existente & 400.000 & $\$ 110,25$ & $(3.628,1179)$ \\
\hline & & & & 181,4059 \\
\hline
\end{tabular}

Demonstrações Contábeis complementares:

Demonstrações de resultados de X1 (\$)

\begin{tabular}{|l|l|l|l|}
\hline & Janeiro & Fevereiro & Acumulado \\
\hline Ganho nos depósitos à vista & 0 & 20.000 & 20.000 \\
\hline Lucro Líquido & 0 & 20.000 & 20.000 \\
\hline
\end{tabular}


Balanços em Moeda de 28.02.X1 (\$)

\begin{tabular}{|l|c|c|}
\hline & $31.01 . X 1$ & $28.02 . X 1$ \\
\hline ATIVO & & \\
\hline Operações & 525.000 & 525.000 \\
\hline & $\mathbf{5 2 5 . 0 0 0}$ & $\mathbf{5 2 5 . 0 0 0}$ \\
\hline PASSIVO & & \\
\hline Depósitos à vista & 420.000 & 400.000 \\
\hline Capital & 105.000 & 105.000 \\
\hline Lucro de exercício & 0 & 20.000 \\
\hline & $\mathbf{5 2 5 . 0 0 0}$ & $\mathbf{5 2 5 . 0 0 0}$ \\
\hline
\end{tabular}

Julgamos ser desnecessário explicar o Fluxo de Caixa de janeiro, pois toda a entrada de caixa foi aplicada em operações de crédito.

Observando as demonstrações de resultados verificamos que, no mês de fevereiro, houve um lucro de \$20.000 que é o próprio ganho com depósitos à vista.

As pessoas não muito afeitas à técnica contábil poderiam dizer que o lucro de fevereiro é fíctício pois, olhando os fluxos de caixa, não vemos entrada de dinheiro em fevereiro.

O lucro é verdadeiro, pois, comparando os balanços em moeda de poder aquisitivo constante, verificamos o acréscimo de Patrimônio Líquido exatamente de \$20.000. O que existe é uma aparente dissociação entre o lucro e o caixa gerado pelos depósitos à vista.

O lucro foi caixa, mas não no mês de sua geração, e sim quando os depósitos a vista entraram na instituição que, em nosso exemplo, foi em janeiro. Afinal, entraram à época $\$ 400.000$, correspondentes a 3.809,523 UMCs (\$ $\$ 20.000 \mathrm{em}$ moeda atual); mas, desse total, a empresa só deve agora 3.628,1179 UMCs (\$20.000 em moeda atual se transformou em lucro para a empresa).

Nota-se que, raciocinando-se dessa forma, fica mais visível o efeito caixa "desse ganho inflacionário".

Para que o ganho nos depósitos à vista possa ser evidenciado e conseqüentemente conciliado com o caixa, vamos apresentar, no Fluxo de Caixa, os depósitos à vista divididos em duas parcelas: \$ 400.000 correspondentes aos depósitos recebidos em janeiro e $\$ 20.000$ relativos ao ganho com esses depósitos.

Assim, o fluxo de caixa acumulado em moeda de 28.02.X1 será o seguinte:

Fluxo de Caixa Acumulado de X1 (\$)

\begin{tabular}{|l|r|}
\hline Ingressos de Recursos & \\
\hline Integralização de capital & 105.000 \\
\hline Depósitos à vista & 400.000 \\
\hline Ganho nos depósitos à vista & 20.000 \\
\hline Total das entradas & $\mathbf{5 2 5 . 0 0 0}$ \\
\hline Aplicação de Recursos & \\
\hline Operações de crédito & 525.000 \\
\hline Variação líquida de caixa & 0 \\
\hline Saldo de caixa 31.01.X1 & 0 \\
\hline Saldo de caixa 28.02.X1 & 0 \\
\hline
\end{tabular}


O que existe, na verdade, é um deslocamento entre o lucro e o caixa gerados pelos depósitos à vista. E não uma dissociação. O problema é que a nova distribuição só pode ser feita agora, quando se sabe quanto do que entrará com o carimbo de "Depósitos à Vista" mudou para o rótulo "Ganho nos Depósitos à Vista".

Como a pesquisa do AICPA mostrou que a maioria das empresas norte-americanas publicaram o Fluxo de Caixa utilizando o Método Indireto, vamos montar um exemplo desse Fluxo de Caixa.

Fluxo de Caixa Acumulado de X1 (\$)

\begin{tabular}{|l|l|}
\hline Das atividades Operacionais & \\
\hline Lucro líquido & 20.000 \\
\hline Caixa Líquido gerado pelas atividades operacionais & 20.000 \\
\hline Atividades de Investimento & \\
\hline Operações de crédito & $(525.000)$ \\
\hline Caixa gerado pelas atividades de investimento & $(525.000)$ \\
\hline Atividades de Financiamento & \\
\hline Integralização de Capital & 105.000 \\
\hline Depósitos à vista & 400.000 \\
\hline Caixa gerado pelas atividades de financiamento & 505.000 \\
\hline Variação de Caixa & \\
\hline Caixa no início do período & 0 \\
\hline Caixa no final do período & 0 \\
\hline
\end{tabular}

Para efeito de ilustração, vamos elaborar também o Fluxo de caixa de fevereiro pelo Método Indireto:

Fluxo de Caixa de fevereiro de X1 (\$)

\begin{tabular}{|l|c|}
\hline Das atividades Operacionais & \\
\hline Lucro Líquido do período & 20.000 \\
\hline Ajustes ao Lucro Líquido & \\
\hline Ganho nos depósitos à vista (não caixa deste mês) & $(20.000)$ \\
\hline Lucro Líquido ajustado & 0 \\
\hline Caixa gerado pelas atividades operacionais & 0 \\
\hline Variação de Caixa & 0 \\
\hline Integralização de Capital & 0 \\
\hline Caixa em 31.01.X1 & 0 \\
\hline Caixa em 28.02.X1 & 0 \\
\hline
\end{tabular}

Podemos concluir, com esse exemplo, que o ganho inflacionário (Lucro Inflacionário) existe (mas não com o entendimento de que ele é oriundo de saldo credor de correção monetária) e que, também todo o lucro inflacionário já foi caixa no dia da entrada do empréstimo subsidiado e, no caso dos Bancos, na data em que os depósitos à vista entraram.

Conforme comentado anteriormente, o seu valor exato só poderá ser calculado quando da apuração do resultado de um período qualquer, compreendido entre a data de entrada de empréstimo subsidiado e/ou depósito à vista (que pode ser considerado um empréstimo subsidiado) e a data do encerramento do exercício, momento em que se conhece a inflação do período.

\section{RESUMO}

Neste artigo, primeiramente, discutimos o surgimento da demonstração do Fluxo de Caixa e os modelos sugeridos pelo FASB e IASC. 
Em seguida, fizemos um estudo sobre o verdadeiro significado da conta de correção monetária e, por meio de exemplos, demonstramos a existência do lucro inflacionário.

Chegamos à conclusão de que o lucro inflacionário é realizado financeiramente, antes mesmo de ser considerado lucro.

Apresentado um modelo simples para o Fluxo de caixa de um Banco, acabamos por demonstrar a influência do ganho com depósitos à vista, no lucro e na montagem desse fluxo.

\section{REFERÊNCIAS BILIOGRÁFICAS}

AICPA - American Institute of Certified Public Accountants, Accounting Trends \& Techniques annual. Surney of Accounting Practices Followed in 600 Stockholders reports, New York, 1993.

BARBIERI, Geraldo - Fluxo de Caixa Modelo para Bancos Múltiplos. São Paulo, 1995. Tese doutorado, Faculdade de Economia, Administração e Contabilidade USP.

FASB - Financial Accounting Standards Board Statement of Cash Flows, Boletim nº 95.

IASC - International Accounting Standards Committee. Cash Flow Statement. IAS 7, Revisão, 1992.

IBRACOM - Instituto Brasileiro de Contadores e IPECAFI - Instituto Brasileiro de Pesquisas Contábeis, Atuariais e Financeiros. Estrutura Conceitual Básica da Contabilidade. São Paulo, 1986.

IOB - Informações Objetivos. Evolução para o fluxo de caixa. (1 $1^{\mathrm{a}}, 2^{\mathrm{a}}$ e $3^{\mathrm{a}}$ partes). Caderno Temática Contábil e balanços. Boletins nºs. 5, 6 e 7. São Paulo, 1988.

IUDÍCIBUS, Sérgio de, MARTINS, Eliseu e GELBCKE, Ernesto Rubens. Manual de Contabilidade das Sociedades por Ações - FIPECAFI, $3^{\text {a }}$ edição, São Paulo, Atlas, 1990.

MARTINS, Eliseu - Contabilidade versus Fluxo de Caixa. Caderno de Estudos, São Paulo, FIPECAFI, n², São Paulo, 1990. 